\title{
NationWide outbreak of Salmonella enterica SEROTYPE GiVE INFECTIONS IN INFANTS IN FRANCE, LINKED TO INFANT MilK FORMULA, SEPTEMBER 2008
}

\author{
N Jourdan (n.jourdan@invs.sante.fr) ${ }^{1}$, S Le Hello², G Delmas ${ }^{1}$, J Clouzeau ${ }^{3}$, C Manteau $^{4}$, B Désaubliaux ${ }^{5}$, V Chagnon ${ }^{6}$, \\ F Thierry-Bled ${ }^{7}, \mathrm{~N}$ Demare $^{8}, \mathrm{~F}$ X Weill ${ }^{2}$, H de Valk ${ }^{1}$ \\ 1.Institut de veille sanitaire, St Maurice, France \\ 2. Centre National de Référence des Salmonelles, Institut Pasteur, Paris, France \\ 3. Hôpital de Niort, service de pédiatrie, France \\ 4. Hôpital de Nantes, clinique pédiatrique, France \\ 5. Direction Départementale des Affaires Sanitaires et Sociales (DDASS) de Loire Atlantique, France \\ 6. Direction Départementale des Affaires Sanitaires et Sociales (DDASS) des Deux-Sèvres, France \\ 7. Direction Générale de la Consommation de la Concurrence et de la Répression des Fraudes (DGCCRF), France \\ 8. Agence Française de Sécurité Sanitaire des Produits de Santé (AFSSAPS), France
}

On Thursday 18 September 2008, the hospital of Nantes in west France informed the District Health Office of a case of salmonellosis in an exclusively bottle-fed infant. On Monday morning 22 September, two additional cases of salmonellosis in infants were reported by the hospital of Niort in southwest France. The serotype of the three cases was unknown at that time.

At the same time, the database of the French national reference centre (NRC) for Salmonella showed a recent increase in the proportion of Salmonella enterica serotype Give isolates from infants. The overall number of S. Give isolates received by the NRC in 2008 was 19 , similar compared to the same period in previous years. However, six of the recent isolates had been obtained from infants, whereas this proportion was zero in previous years.

\section{Epidemiological investigations}

An investigation was started to identify any common exposures between the three reported cases of infant salmonellosis, and to identify the serotype(s) involved. In addition, we investigated the cases of S. Give in infants identified by the NRC.

The parents of the three reported infant salmonella cases were interviewed by the district health office on their consumption of foods and drink and other exposures. The infants, aged 9 weeks, and 4 and 5 months respectively, had developed symptoms of febrile diarrhoea between 13 and 18 September and had been hospitalised between 17 and 19 September. The infants had not been in contact with other diarrhoea cases, and had no common exposures except for their infant formula milk. All three drank the same brand (brand $\mathrm{X}$ ) formula milk. The batch number of the product consumed during the days before the onset of symptoms was known for two cases. The serotype of one of the three isolates was known on 25 September and confirmed as Give.

As of 25 September, five of the six infant cases of S. Give in the NRC database have been investigated. The infants are between 1.5 and 4.5 months of age and live scattered throughout France. They developed symptoms between 17 and 28 September: all had diarrhoea, which was bloody for four infants, four had fever, and two were hospitalised. The parents of all five infants reported feeding their infants the same brand $X$ of infant powdered formula milk in the week before onset of symptoms. The batch number is known for one case and it is the same batch as in the two cases mentioned above. No other common exposures were identified.

The preliminary results of the investigation strongly suggest the brand $X$ formula milk as the vehicle of transmission. On 22 September, the authorities and the producer decided to recall the incriminated batch. On 23 September, the producer initiated the recall of this batch. On 24 September, the recall was extended to all batches since consumers had difficulties identifying the batch number. Consumers have been advised not to drink the product and to return it to the place of sale.

Investigations are ongoing, particularly microbiological examination of the product and investigations of additional infant salmonellosis cases. Since the recall, five additional cases of infant salmonellosis have been reported. All five infants had consumed the incriminated product before illness. The isolates of these cases are currently being serotyped

\section{F I G U R E 1}

Cases of Salmonella Give infection in infants, by week of onset of symptoms, France, August - September 2008

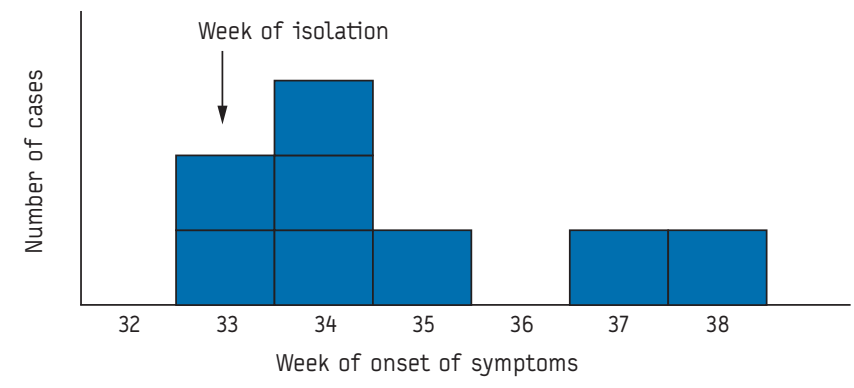


A European alert was issued by France through the Rapid Alert System for Food and Feed (RASFF) on 23 September.

A warning was posted on the European Early Warning and Response System on 25 September, and information was sent via the European Food and Waterborne Diseases and Zoonoses Network at the European Centre for Disease Prevention and Control (ECDC).

This article was published on 25 September 2008.

Citation style for this article: Jourdan N, Le Hello S, Delmas G, Clouzeau J, Manteau C, Désaubliaux B, Chagnon V, Thierry-Bled F, Demare N, Weill FX, de Valk H. Nationwide outbreak of Salmonella enterica serotype Give infections in infants in France, linked to infant milk formula, September 2008. Euro Surveill. 2008:13(39):pij=18994. Available online: http://www.eurosurveillance.org/ViewArticle.aspx?ArticleId=18994 